\title{
Hybrid High-Impact Pedagogies: Integrating Service-Learning with Three Other High-Impact Pedagogies
}

\author{
Robert G. Bringle \\ Indiana University-Purdue University Indianapolis
}

\begin{abstract}
This article proposes enhancing student learning through civic engagement by considering the advantages of integrating service-learning with study away, research, and internships and pre-professional courses into first-order, second-order, and third-order hybrid high-impact pedagogies. Service-learning contributes numerous attributes to the other pedagogies (e.g., civic learning, regular and structured reflection, reciprocal partnerships, diversity, democratic values) that can produce outcomes that are more extensive, more robust, more transformational, and more distinctive than traditional pedagogies or a single highimpact practice. Possibilities for future research and implications for course design and implementation are proffered.
\end{abstract}

Hybrid High-Impact Pedagogies: Integrating Service-Learning With Three Other HighImpact Pedagogies

"To institutionalize service-learning effectively, service-learning must be viewed not as a discrete 'program' but as a means to accomplish other important goals of the campus" (Holland \& Furco, 2004 , p. 39). This quote captures an important strategy that service-learning, in particular, and civic engagement more generally, must enact to be integral to higher education in the future: connecting civic engagement initiatives, values, and goals to other initiatives on campuses. Bringle, Games, and Malloy (1999a) reflected this position when they posed the following question to scholars in the field and asked them to respond: What would the academy look like if we took Ernest Boyer's vision for the New American College seriously? Those scholars linked service-learning and civic engagement to an examination of Boyer's role as a leader in education (Glassick, 1999), the values of the academy (e.g., leadership, service, and democracy) (Astin, 1999), institutional mission (Holland, 1999), infrastructure and organizational structure (Singleton, Hirsch, \& Burack, 1999; Walshok, 1999), pedagogy (Zlotkowski, 1999), faculty roles and rewards (Plater, 1999), and assessment (Cambridge, 1999). Their exploration acknowledged that service-learning and civic engagement can be a catalyst for institutional change but, more importantly, service-learning and civic engagement can be integrated with and improve in significant ways different aspects of the work of the academy that would lead to an acknowledgement of "value add- ed." They asserted that service-learning and civic engagement can provide "a means for reaching and enhancing the most fundamental purpose of educating their constituencies and fulfilling their mission in ways that benefit the greater society, produce a more civil society, and strengthen democracy" (Bringle, Games, \& Malloy, 1999c, p. 202).

Nothing is more central to higher education than student learning. How can student learning be improved? Kuh $(2009,2012)$ has identified the following educational practices as high-impact practices: First-year seminars and experiences, common intellectual experience, learning communities, writingintensive courses, collaborative assignments and projects, undergraduate research, diversity/global learning, service-learning, internships, and capstone courses and projects. His analysis of highimpact practices is based on students' self-reported gains of deep learning, general learning, personal growth, and practical gains attributed to these different educational activities. He assumed that highimpact practices produce these results because they are accompanied by higher expectations for student achievement, result in enhanced time and effort by students, produce greater student engagement with faculty and peers, provide opportunities for more frequent feedback, help students reflect on and integrate their learning, increase students' interactions with diverse others, result in the transfer of learning to other settings, provide authentic ways for students to demonstrate their competence, and result in enhanced clarity about students' educational and life goals (Kuh, 2009, 2012). He recommended that campuses have every student participate in at least two high-impact educational activities, preferably 
one in the first year and one in the student's major field of study (Kuh, 2009).

This article builds upon the vision of enhancing student learning through civic engagement by considering the advantages of integrating several highimpact educational practices. Specifically, the analysis explores, examines, compares, and contrasts integrating (a) service-learning, (b) study away, (c) research, and (d) internships and pre-professional courses, with a specific focus on integrating servicelearning with the other three. These four educational practices were selected because they are rather distinct pedagogical approaches regarding teaching practices and learning objectives. Learning communities, first year seminars, capstones courses, and common intellectual experiences are generally curricular locations or formats for instruction rather than types of pedagogies, and they can incorporate any of these four (e.g., a learning community could include service-learning; a capstone course could focus on research). Furthermore, the four high-impact practices that will be the focus of this analysis can incorporate intensive writing and collaborative learning.

\section{Four High-Impact Practices}

All four high-impact practices used in this analysis are viewed as serious academic work that have or should have, the following attributes of good experiential education: (a) course content and learning objectives; (b) activities (e.g., in a community, in a laboratory, in a classroom); (c) systematic, structured, and regular reflection that connects course content to the activities; and (d) assessment of learning (not just monitoring participation in an activity) (Bringle \& Plater, 2017). In all cases, all four of these attributes must be present in order for the educational experience to be credit bearing and appear on a transcript. These attributes provide a basis for evaluating the design, implementation, and outcomes associated with each type of highimpact pedagogy.

\section{Service-learning}

Service-learning is the intersection of teaching and service and it has dual purposes of benefiting the community and fulfilling academic learning goals (Bringle, Games, \& Malloy, 1999b). Servicelearning as a form of civic engagement is defined as a

course-based, credit-bearing educational experience in which students (a) participate in mutually identified and organized service activities that benefit the community, and (b) re- flect on the service activity in such a way as to gain further understanding of course content, a broader appreciation of the discipline, and an enhanced sense of personal values and civic responsibility. (Bringle \& Clayton, 2012, p. 105; adapted from Bringle \& Hatcher, 1996, p. 222)

This definition illustrates key attributes of servicelearning as a pedagogy: (a) it is distinct from volunteering because it is course-based and is focused on educationally-meaningful community service for which credit is based on the learning that occurs and not just completing the service hours; (b) it involves intentional collaboration with community partners to design, implement, and evaluate the educational experiences for student learning and the community's benefits; (c) the communitybased activities are intentionally identified to fulfill the goals of different constituencies (e.g., faculty, students, community partners); (d) reflection activities are designed to link the community service and the academic content in ways that generate, deepen, and capture learning (Ash \& Clayton, 2009a, 2009b); and (e) in addition to academic learning, it also identifies personal growth and civic learning as intentional learning goals for the educational experience (Stokamer \& Clayton, 2017). This definition aligns with Furco's (1996) position that service-learning courses are "distinguished from other approaches to experiential education by their intention to equally benefit the provider and the recipient of the service as well as to ensure equal focus on both the service being provided and the learning that is occurring" (p. 5). The nature of the community-based activities may be direct service (e.g., to clients of a non-profit agency), indirect service (e.g., constructing a web page for a non-profit agency), research (to be discussed subsequently as participatory community action research), and/or advocacy (e.g., working with neighborhood residents to rally support for or against a proposed government policy) (Bringle, Reeb, Brown, \& Ruiz, 2016). Assessing learning can be based on evaluations by community partners and peer students, self-reports from students, reflection products that can provide authentic evidence of learning, and traditional assessments of learning (Clayton, Bringle, \& Hatcher, 2013; Hatcher, Bringle, \& Hahn, 2017b).

\section{Study Away}

Kuh (2009) identifies diversity/global learning as a high-impact practice that allows students to "explore cultures, life experiences, and worldviews different from their own" (p. 20). However, Kuh notes that "Frequently, intercultural studies are aug- 
mented by experiential learning in the community and/or by study abroad" (p. 20). Consistent with Kuh's point, emphasizing active and experiential learning practices is central to the current analysis, but especially experiential activities that involve students in unique communities through reciprocal relationships. Well-designed service-learning inherently encompasses those types of diversity experiences. This leaves study abroad as the remaining element of Kuh's description of this highimpact practice. However, for purposes of this analysis, this high-impact practice will be reframed as study away (Sobania, 2015; Sobania \& Braskamp, 2009), which encompasses immersive study abroad and immersive domestic educational experiences intentionally designed to achieve educationallymeaningful diversity and multicultural experiences. The experiential component of study away is contained in the change of venue and interactions with those in the venue, whether that is local, national, or international. The degree to which the new setting is linked to the academic work will vary from accidental to intentional. Generally speaking, the more intentional the courses are in design, implementation, and assessment, the more frequent and the better structured the reflection will be on the connections among the academic content, experiential activities, cultural context, diversity-based learning objectives, and assessment. Assessing learning may occur through assessment in individual courses (e.g., a grade at a foreign university in a particular course), or it can encompass a more holistic assessment of the different types of learning using a variety of assessment techniques and evidence (Bringle, Hatcher, \& Jones, 2011; Savicki \& Brewer, 2015).

\section{Research}

Kuh (2009) identifies research experiences as having the goal "to involve students with actively contested questions, empirical observation, cutting-edge technologies, and the sense of excitement that comes from working to answer important questions" (p. 20). Although the Council on Undergraduate Research provides guidelines for providing high-quality research experiences for students (Hansel, 2012), not all undergraduate research experiences possess these qualities. At one end of the spectrum, undergraduate laboratories may have students conduct canned experiments or students may perform menial tasks for a faculty member's research project. At the other end of the spectrum are mentored research experiences in which students are co-creators and collaborators with faculty in conceptualizing, designing, executing, analyzing, preparing reports, and disseminating results that contribute to generalizable knowledge. These latter cases will be the focus of the current analysis because they most clearly integrate both content and research activities. Linking the two may occur during the development of the research (e.g., writing a research proposal) and writing a final report. The quality of the outcomes can be assessed by student peer evaluations, instructors, faculty mentors, and other professionals through peer review.

\section{Internships}

Kuh (2009) notes that the purpose of an internship is to:

provide students with direct experience in a
work setting - usually related to their career
interests - and to give them the benefit of su-
pervision and coaching from professionals in
the field. If the internship is taken for course
credit, students complete a project or paper that
is approved by a faculty member. (p. 21)

For purposes of the current analysis, the nature of internships is expanded to encompass many forms of pre-professional and career-oriented experiential courses that may not carry the title "internship." These would include pre-professional courses such as work-integrated learning (e.g., Higher Education Quality Council of Ontario, 2016), practica, pre-service student teaching in teacher education, field placements, and clinical rotations in the health sciences (e.g., nursing). Too often internships are heavily focused on the activity at the placement site, but vary greatly in terms of the relationship of the activity to course material (either current course content or content from past courses), reflection, and assessment (Bringle \& Plater, 2017). O'Neill (2010) describes how they can be intentionally designed around clear learning objectives and incorporate regular and structured reflection. As Kuh (2009) notes, an internship may require a project or paper at the end of the semester. This reflects an inherent deficiency of what is probably the modal implementation of internships: one-time assignments for students to reflect on the educational nature of their activities rather than students having regular and structured opportunities for reflection that connect the activities to course material and provide a basis for regular feedback and assessing learning. Because of their focus on careers and professional preparation, internships and pre-professional courses will be combined into a single teaching practice. 


\section{Hybrid High-Impact Pedagogies}

High-impact practices identified by Kuh (2009, 2012) can be recommended on the basis that they produce good learning outcomes when well implemented. The thesis of the current analysis is based on the promise that the intentional integration of high-impact practices, or hybrid high-impact pedagogies, has the potential to produce even stronger, broader, more enduring, and deeper learning outcomes, compared to the individual component pedagogies and compared to traditional pedagogies. Currently, this is speculation that warrants empirical evaluation. All of the high-impact practices can occur in combinations that define hybrid pedagogies. Kuh (2009) noted that it is not unusual for capstone experiences to focus on research, including independent, mentored research. Hansen and Hahn (2016) presented analyses of the merger of learning communities and first-year seminars (also see Henscheid, 2000) as well as service-learning and learning communities. Swaner and Brownell (2009) concluded that "stand-alone first-year seminars and those linked to a learning community support the contention that these connections lead to better outcomes for students" (p. 124), a finding consistent with research by Hansen and Hahn. Mayhew and Engberg (2011) found service-learning incorporated into first-year seminars improved students' charitable responsibility (also see Barefoot, 2008). Henscheid presented cases of campuses that combined learning communities, first-year seminars, and service-learning. Kecskes and Kerrigan (2009) describe the integration of community engagement experiences into capstone courses. Many other combinations of high-impact practices are possible and warrant analysis and evaluation. The current analysis is focused on hybrid high-impact pedagogies that result from service-learning being integrated with study away, research, and internships/ pre-professional courses.

\section{First-Order Hybrid High-Impact Courses}

First-order hybrid high-impact courses are paired combinations of high-impact practices. Just as service-learning is not the addition of a community service activity to a course but rather the intentional integration of community-based activities that meet learning objectives as well as benefit the community, these hybrid high-impact courses are, similarly, viewed as encompassing the intentional integration of two high-impact pedagogies in the design and implementation of a course. The combination of two or more poorly designed high-impact practices could result in a low quality educational experience. However, through good design and intentional integration, the positive attributes of each component high-impact pedagogy can contribute to the hybrid course. Because the primary focus of this analysis is on first-order hybrids that include service-learning, the other three identified in Table 1 (immersive research, immersive internship, and research internship) will not be discussed here. These other three first-order hybrids may produce outcomes that exceed those attained with a single high-impact practice. Unfortunately, even if they do, they would most likely fall short on one or more of the attributes and outcomes that service-learning offers to hybrids courses (e.g., civic learning, regular reflection, reciprocal partnerships, diversity, democratic values).

\section{Table 1}

\section{Hybrid High-impact Pedagogies}

High-Impact Practices*

A. Service-learning*

B. Study Abroad/Away Immersion*

C. Undergraduate Research*

D. Internships*

First-Order Hybrids*

Immersive Service-learning (A \& B)*

Participatory Community Action Research (A \& C)*

Civic Internship/Pre-Professional (A \& D)*

Immersive Research (B \& C)

Immersive Internship/Pre-Professional (B \& D)

Research Internship (C \& D)

Second-Order Hybrids*

Immersive Participatory Community Action Research (A \& B \& C)*

Immersive Civic Internship/Pre-Professional (A \& B \& D)*

Participatory Community Action Research Internship/Pre-Professional (A \& C \& D)*

Immersive Research Internship (B \& C \& D)

Third-Order Hybrid*

Participatory Community Action Research Immersive Civic Internship/Pre-Professional $(\mathrm{A} \& \mathrm{~B} \& \mathrm{C} \& \mathrm{D})^{*}$

Note: Asterisked entries are discussed in detail.

Immersive service-learning. Immersive servicelearning is the hybrid high-impact pedagogy that integrates study away from the campus for a significant period of time with a service-learning experience. Immersive service-learning could occur in a setting that is local (e.g., inner city), national (e.g., tribal college), or international (e.g., study abroad). These can be short term (e.g., 1 to 10 weeks; Bowman, Brandenberger, Mick, \& Smedley, 2010; Jones, Rowan-Kenyon, Ireland, Niehaus, \& Skendall, 2012; Sobania, 2015), or a semester or academic year, and they can occur in various formats (Jones 
\& Steinberg, 2011). The presumption is that immersive service-learning courses are academically based and involve credit bearing coursework linked to community-based activities in the new venue. Assessment can be based on qualitative (Jones \& Foste, 2017; Kiely \& Hartman, 2011), quantitative (Steinberg, Bringle, \& McGuire, 2013), or mixed methods approaches.

International service-learning is a subset of immersive service-learning and is viewed as the intersection of (a) service-learning, (b) study abroad, and (c) international education (Bringle \& Hatcher, 2011). When well-designed and well-implemented, international service-learning can have powerful outcomes (e.g., Hartman \& Kiely, 2014). However, too often, traditional study abroad has the student and student outcomes as the primary if not the sole rationale for the experience (i.e., if students could not return with course credits from study abroad, they would be less like to engage in it). Therefore, most traditional study abroad does not link or only weakly links the student and the venue of study in any intentional way. Hovey and Weinberg (2009) distinguish "low road" from "high road" study abroad programs. Low-road experiences provide superficial exposure to a host region - students "simply get the American college experience in a different time zone" (p. 36). In contrast, high-road study abroad emphasizes international education - the experience is designed to "ensure deep cultural and linguistic immersion" and to "understand and respect local customs" (p. 37). International service-learning broadens the perspective of goals and outcomes beyond the individual student. Through community-based activities that provide immersion in a local culture, possibly augmented with homestays, international service-learning as a form of immersive service-learning emphasizes working with community partners to their benefit, learning about and from local cultures and customs, regular and structured reflection on how these experiences are related to course content (Whitney \& Clayton, 2011), and enrichment of civic education through consideration of power and privilege (Bringle et al., 2011; Green \& Johnson, 2014). These are qualities that may be lacking as intentional design features in most, if not all, traditional study abroad experiences.

Participatory community action research. The merger of service-learning and research into participatory community action research (PCAR; also referred to as community-based participatory research) produces first-order hybrid high-impact courses that have distinctive pedagogical and epistemological attributes (Gibbons et al., 1994; Strand, Marullo, Cutforth, Stoecker, \& Donohue, 2003;
Van de Ven, 2007). Student participation in PCAR could occur within a course (e.g., Kowaleski, 2004) or as independent study for credit. PCAR can also occur in multi-disciplinary teams that are coordinating activities on a social issue and the community activities can span several different courses within a discipline and across disciplines (see Reeb, Glendening, Farmer, Snow, \& Elvers, 2014, for an example). The addition of service-learning to research adds a civic component to traditional research. As Minkler and Freudenberg (2010) note, PCAR

can be an important tool in efforts to move from data gathering and interpretation to the use of findings in ways that . . influence the lives of a large number of people. Policyfocused [PCAR] can identify, make visible, and legitimize issues so that they ... are placed on the public's agenda. It can . . . help partnership members bring the attention of . . . mass media to long ignored issues - or newly uncovered problems - based on findings that are both newsworthy and grounded in strong evidence. (pp. 290-291)

Bringle et al. (2016) identify epistemological characteristics of PCAR as including:

production of knowledge in a context of ap-
plication; emphasis on social accountability;
recognition of multiple knowledge-production
sites beyond the university; co-ownership of
data; emphasis on collaboration (i.e., utilizing
input from multiple stakeholders); multiple
modes of dissemination of research tailored to
different audiences; recognition of beneficia-
ries of research beyond academic researchers;
and examining, interpreting, and integrating
research findings from multiple perspectives
and methodologies. (p. 45)

The PCAR activities could be focused on direct service (e.g., conducting a survey of residents in collaboration with a neighborhood association), indirect service (e.g., designing an evaluation of a program in collaboration with staff to support a grant application), research (e.g., conducting research with a neighborhood association to evaluate theories for increasing citizen involvement), or advocacy (e.g., conducting research with a neighborhood association that provides a basis for arguing for or against a policy issue). Reflection that connects the content of the research to the activities, including collaboration with community partners, can occur at various stages of the research process. This should include not only the academic content implicated in the research, but also students' personal growth and civic learning. Assessment would 
include learning objectives associated with research methods, social issues, and diversity issues as well as how the community benefited from the research results.

Civic internship/pre-professional courses. The civic internship/pre-professional (CIPP) hybrid combines the best attributes of pre-professional and career-oriented courses with service-learning in a manner that provides pre-professional experiences that contribute to a students' career trajectory as well as their personal and civic development. CIPP courses can occur in any sector of society: for profit, government, not-for-profit, or in communities. However, what service-learning brings to the CIPP hybrid is an intentional civic educational component that contributes to students becoming civicminded professionals (Hatcher, 2008). The civic component of CIPP courses can result from the nature of the setting or organization, communitybased activities that focus on a social issue from the perspective of a profession, key readings that provide a basis for analyzing and understanding a social issue, and regular reflection activities intentionally designed to explore the civic aspects of the CIPP activities (Ash \& Clayton, 2009a). Furthermore, service-learning's values encompass democratic principles that are characterized by three key processes: being fair, inclusive, and participatory (Saltmarsh, Hartley, \& Clayton, 2009). The salience of these qualities in the design and implementation of a CIPP course can contribute to the civic education of students for their future lives and careers. These are likely absent from most internships and pre-professional courses except in a few instances (e.g., social work, community nursing).

Service-learning stresses the importance of reflection that connects theory to practice, occurs regularly, is structured, results in feedback from others (e.g., students, peers, experts), and provides opportunities for exploring and developing values as part of the teaching process (Bringle \& Hatcher, 1999). As Kuh (2012) notes, "Working on clearly structured meaning-constructing assignments, engaging in interactive writing activities, and receiving feedback are each more important than the amount of writing that students do." Designing reflection activities around clearly articulated learning objectives, including civic learning objectives, is central for them to generate, deepen, and capture students' academic learning, civic learning, and personal growth (Ash \& Clayton, 2009a, 2009b; Bringle et al., 2016). Thus, the merger of service-learning with pre-professional and internship experiences into a CIPP course can enrich internships by expanding learning objectives to include civic learning; by intentionally incorporating academic con- tent; and by enhancing regular, structured reflection during the community-based activities. Assessment would include the ways in which the experiences contribute to professional and civic competencies as well as the degree to which there are benefits to civil society and community partners.

\section{Second-Order Hybrid High-Impact Courses}

Second-order hybrid high-impact courses are the fusion and integration of three types of high impact practices. The three second-order hybrids that include service-learning will be discussed; immersive research internship will not be discussed further because of the current focus only on pedagogical hybrids that include service-learning.

Immersive PCAR. Immersive PCAR is a secondorder hybrid of research, service-learning, and immersion in a novel local, national, or international context. The course provides the basis for students to conduct research as part of a community and with community partners. Much like the previous first-order hybrids, this hybrid reflects servicelearning's values and attributes of working with community partners in democratic ways that result in research projects that are mutually beneficial to students and communities and that can inform the discipline or profession. Because the immersion is in a new venue or culture, preparation of students for the intercultural experiences is imperative (Bringle et al., 2011).

Immersive CIPP. Immersive CIPP incorporates immersion into a unique context that provides opportunities for working with diverse cultures on activities that matter to them as well as to the students' future careers. Learning objectives for these courses can integrate content from past courses and new academic content with the activities and the cultural context within which students are immersed. Students can work with community partners to identify the most appropriate activities in which to engage so that community interests and outcomes shape the choice of activities. Students work with community partners, both professionals and non-professionals, who can provide feedback on the development of their professional competencies. Regular structured reflection can also provide opportunities for feedback and assessment of learning (e.g., research skills, intercultural competency, professional skills) that result from the activities and experiences (Whitney \& Clayton, 2011).

PCAR CIPP. A PCAR CIPP course combines service-learning and research with CIPP courses to provide opportunities for students to conduct community-based research activities that benefit communities, that are consistent with the students' 
career goals, and that contribute to their academic skills and civic knowledge. This hybrid is more than merely having students conduct applied research in a community because, as previously noted for CPAR, service-learning contributes a civic dimension that is explored and deepened through design and implementation of the research, puts an emphasis of collaborating with community partners on all aspects of the research, incorporates working with diverse populations, and involves regular and structured reflection. These community-based, preprofessional research experiences, when combined with service-learning, also stress the importance of working with community partners on the research activities so that they are co-researchers and the results have relevance to them.

\section{Third-Order Hybrid High-Impact Courses}

\section{PCAR Immersive CIPP. PCAR immersive CIPP} is a third-order hybrid that integrates all of the powerful attributes of the four high-impact pedagogies. All of the comments previously made about the strengths of the component high-impact practices and previous hybrids apply to this third-order hybrid. Thus, the brevity of discussion here is not an indication of the relative importance of this hybrid. In contrast, this may be the most powerful pedagogy of them all, but that is yet to be determined. Students in these courses are immersed in a novel setting, work democratically with professionals and community members in that context, and conduct research that contributes to their educational goals and career trajectory as well as contributes to the host community. Because these courses are aligned with professional interests and preparation for careers, students are likely to be very engaged and motivated in these experiences.

The addition of service-learning can contribute in significant ways to producing civic-minded professionals (Hatcher, 2008). One can imagine that a third-order, hybrid, high-impact course is ideal for social work students who intend to enter careers focused on studying and conducting research on the effectiveness of various types of community initiatives or intervention programs directed at particular groups; community nursing students who are interested in a career that includes research on a community health issue in special populations; psychology students who want to pursue careers in which they conduct research on community issues related to social justice and policy for underrepresented groups; or engineering or science students who want to conduct research on an environmental issue (e.g., solar energy in remote sites, conducting research to efficiently improve water quality in an international setting) in a particular geographic region after graduation. The Indiana University School of Dentistry has dental students working with Mexican dental students on research that contributes to local knowledge about oral health issues, enhances the U.S. students' understanding of how context and culture are factors in oral health, enhances intercultural competency, and provides all students with opportunities to improve their research skills (Maupome et al., 2013).

\section{Discussion}

Civic engagement has the promise to be a mechanism through which many aspects of higher education can be quantitatively improved (better student learning, more meaningful civic research and scholarship, better community-campus partnerships) and qualitatively changed (instituting democratic practices in an institution that is not particularly democratic; Saltmarsh et al., 2009). Bringle et al. (1999c) noted that the "fundamental challenge" raised in the analysis by the scholars who contributed to their book "is to the character of higher education, including the underlying rationale, philosophy, and motivation for developing campus citizenship within the local, national, and international context" (p. 202). Although there are critics of civic engagement who have suggested that progress has been slow, incomplete, or has otherwise fallen short of producing systemic changes in higher education institutions (e.g., Saltmarsh et al., 2009), there has been some change and the trajectory is continuing for the academy to be more civically engaged with communities. Although institutions vary in the relative importance of student learning (vs. scholarship and research) and in their motivation to improve learning outcomes, student learning remains central to all types of institutions of higher education and their missions.

If nothing is more central to the mission of higher education than student learning, then civically engaged learning is central to the civic transformation of higher education and democratic engaged learning is central to the democratic transformation of high education (Bringle, Clayton, \& Bringle, 2015; Bringle, Clayton, \& Plater, 2013; Saltmarsh et al., 2009). Service-learning is an important mechanism for producing more civically engaged courses, better student civic learning, and, most importantly, better student learning. However, more and better service-learning is not the final goal of civic engagement but, rather, it is a component of the work that can be viewed as central to the continued integration of civic engagement into all of the work and infrastructure of the academy: teach- 
ing, research, and service (Bringle et al., 2009a). Thus, service-learning, when well-designed and well-implemented, is an important means for modeling civic engagement. It has the advantage that it involves faculty, the curriculum, community partners, and a broadened perspective on student learning outcomes beyond only cognitive academic content. Implementing service-learning and integrating it with other high-impact practices faces the challenge of competing priorities on faculty time, the lack of recognition that improving learning has in faculty roles and rewards, management of community-based activities, the lack of resources to support innovative curriculum development, and the lack of good models of hybrid high-impact pedagogies (Jacoby, 2014). However, instructors have demonstrated that there can be sufficient rewards for themselves, their students, and their community partners to sustain innovative and more effective teaching.

Meta-analyses support the value added by servicelearning to different domains of student learning (Celio, Durlak, \& Dymnicki, 2011; Conway, Amel, \& Gerwien, 2009; Novak et al., 2007; Warren, 2012; Yorio \& Ye, 2012). Finley (2011) found that servicelearning (vs. the other high-impact pedagogies studied) had "the greatest impact on each of the four outcomes measured, regardless of whether the student was in the first or senior year" (p. 2). Making service-learning a pervasive and an expected aspect of the curriculum at all levels and in all majors can stimulate the integration of civic engagement across all areas of academic work: teaching, research, and service (Bringle et al., 1999b). For these reasons, the current analysis is focused on those hybrid highimpact pedagogies that integrate service-learning with the three other high-impact practices. Incorporating these hybrid high-impact practices can result in more extensive development of the public purposes of higher education.

Improving student learning is possible and there is increasingly convincing evidence about what produces the best learning in college students (Pascarella \& Terenzini, 2005). One example of a synthesis of research offered by Marchese (1997) includes the following attributes for achieving indepth learning: (a) active learning; (b) frequent feedback from others (e.g., instructors, other students, community members); (c) collaboration with others; (d) cognitive apprenticeship (i.e., mentored relationships in which students can discuss and learn generalization of principles, transfer of knowledge between theory and practice, and analysis of perplexing circumstances); and (e) practical applications that involve students in tasks that have real consequences with a safety net as a buffer against high-stakes mistakes. Generally, the four high-impact practices used in this analysis, and thus the hybrid high-impact pedagogies, when implemented well, are expected to align well with these attributes and they should produce correspondingly deeper learning. Additional alignment with the hybrid high-impact pedagogies is presumed to be the case for the mediating variables that Kuh identified: (a) enhanced time and effort by students, (b) greater student engagement with faculty and peers, (c) more opportunities for more frequent feedback, (d) students reflecting on and integrating their learning, (e) increased student interactions with diverse others, (f) transfer of learning to other settings, (g) authentic ways for students to demonstrate their competence, and (h) enhanced clarity about students' educational and life goals (Kuh, 2009, 2012).

In addition, Hatcher, Bringle, and Hahn (2017a) identified six attributes of service-learning courses that can vary in intensity and that can be related to student outcomes: degree of (a) reciprocity in community partnerships, (b) integration of communitybased activities and academic content, (c) emphasis on civic learning outcomes, (d) diversity experiences, (e) critical reflection guided by student learning objectives, and (f) use of assessment for course improvement. These attributes are not only relevant to service-learning courses but also the hybrid highimpact courses presented and discussed. However, the presence in hybrid high-impact pedagogies of the attributes identified by Marchese, Kuh, and Hatcher and colleagues warrants assessment as does establishing their relative contributions to student outcomes (i.e., academic learning, civic learning, personal growth) and community outcomes.

Too little attention in research on service-learning and high-impact practices has been directed at the nature of the intervention - the course. Just as meaningful research results are contingent on the quality of the measured outcomes (e.g., psychometric qualities of various measures; Bringle, Phillips, \& Hudson, 2004; high quality quantitative and qualitative research designs; Jones \& Foste, 2017; Patton, 2013; Steinberg et al., 2013), there should be parallel assessment from different perspectives (e.g., student, faculty, community partner) of various qualities of the course as designed and implemented. This assessment should be connected to the presumed underlying course attributes and mediating variables relevant to outcomes being measured, and must transcend the rather superficial aspects of service-learning courses currently being measured (e.g., number of hours of service, direct vs. indirect service). The quality of any course and its intended outcomes will vary depending on factors identified by Kuh, Marchese, and Hatcher and colleagues 
as well as other factors such as the experience of the instructor with the pedagogy, the clarity of the learning objectives, nature of partnerships, the design of the course, the fidelity to principles of good practice with which it is implemented, how formative information is used to adjust the implementation of the course, and how summative information is incorporated into revisions. Not all of the attributes identified by Marchese, Kuh, and Hatcher and colleagues will be present in any particular course, including the high-impact pedagogies and the hybrid high-impact pedagogies. An empirical question that warrants assessment is, Are those attributes more prevalent in high-impact practices? If so, which attributes are associated with which learning outcomes and which ones generally produce better learning outcomes when they are present? A corollary question is, Are they more prevalent in hybrid high-impact pedagogies identified in this analysis than in a single high-impact practice? Hybrid highimpact pedagogies may be the best way to improve student engagement, student learning, student persistence and retention, and student civic preparation for their post-graduate lives. This warrants empirical evaluation in longitudinal studies across various educational experiences of students in different majors and for students at different types of institutions (Hill, Pasquesi, Bowman, \& Brandenberger, 2017; Janke \& Domagal-Goldman, 2017). Any research answering these questions, though, must consider the quality of the design and implementation of the course as well as moderator variables (i.e., what students bring to the course) and mediating variables (i.e., what intervening variables occur during the course that are associated with various outcomes; Steinberg et al., 2013).

Concerning the individual four high-impact pedagogies incorporated in this analysis, Kilgo, Sheets, and Pascarella (2015), using the Wabash National Study of Liberal Arts Education, conducted analyses on over 2,000 students from 17 four-year institutions. Participation in research was associated with gains on critical thinking, interest in lifelong learning, need for cognition, two measures of intercultural effectiveness, and socially responsible leadership. Study abroad and service-learning were associated with gains on two measures of intercultural effectiveness and socially responsible leadership. Internships were associated with higher need for cognition, two measures of intercultural effectiveness, and socially responsibly leadership. Therefore, without considering the quality of the course, research supports the potency of these high-impact practices. Future research needs to investigate the extent to which integrating these pedagogies into well-designed and well-implemented hybrid courses reproduces these results, exceeds these results, and/or produces other learning outcomes (e.g., civic learning, personal growth).

Kilgo et al. (2015) attempted to control for some pre-existing variables, but generally research on service-learning and high impact practices suffers from a major confounding variable: self-selection of students into these educational experiences. For example, Eyler, Giles, and Braxton (1997) found that students who chose service-learning differed from those who did not on pre-service attitudes, skills, values, and understanding of social issues. This issue must be addressed if future research is to provide clarity about the effectiveness of the various pedagogical approaches across a broad range of students and why they produce particular results (Steinberg et al., 2013; Hill et al., 2017). A second major shortcoming to past research is over reliance on students' self-reported outcomes versus the use of authentic evidence of learning outcomes. Selfreport measures can provide a basis for understanding students' attitudes, behavioral intentions, past behaviors, and beliefs. Although self-report instruments can be useful (Bringle et al., 2004), they can also be influenced by social desirability response set, inaccuracies, not accurately reflecting processes that determined outcomes, and being based on inaccurate or biased memories (Kolek, 2013; Steinberg, Bringle, \& Williams, 2010). Self-assessments of skill, character, and learning are particularly flawed (Bowman \& Seifert, 2011; Dunning, Heath, $\&$ Suls, 2004).

Finley and McNair (2013) noted that Kuh's recommendation that students have two high-impact practice courses suggests "that by treating these practices as a set of effective tools rather than as discrete experiences, faculty, administrators, and other campus professionals could begin to conceptualize the collective impact these practices have on indicators of student success and learning" (p. 1). Their analyses indicated that having participated in more high-impact practices resulted in students' higher perceived engagement in deeper learning, general learning, practical competence, and social and personal development. Their results also demonstrated that the cumulative effect for multiple high-impact practices held for African American, Hispanic, Asian American, and white students as well as first-generation students and transfer students. Combining pedagogies into hybrid highimpact courses might produce similar or greater learning outcomes for various student populations, but this warrants empirical evaluation. Further research on hybrid high-impact pedagogies can investigate the generalizability of these findings for these and other student characteristics. 
In addition to the mediating variables identified by Kuh, Marchese, and Hatcher and colleagues, Staub and Finley (2009) identified two common features that successful engaged pedagogies had: (a) they encouraged critical thought and exploration on social or political topics in ways that activated student interest; and (b) they created social networks through peer-to-peer and facultyto-student ties. Concerning the second factor, generating social capital was related to four features of the course implementation: (a) meaningful social interactions, (b) opportunities for reflection, (c) sources of emotional supports, and (d) providing a protective shield against the use or abuse of alcohol. The addition of service-learning to the other three high-impact practices should enhance each of these, but that needs to be assessed systematically.

Bringle and Hatcher (2011) asked the question,

what if higher education identified a pedagogical approach that had educational outcomes that are extensive (influences a broad array of desirable educational outcomes), robust (are evident across a variety of conditions and for a wide range of students), transformational (produces deep, permanent changes in present and future lives), and distinctive (produces educational outcomes that are not as effectively attained using other pedagogies)? (p. 3)

They then speculated that international servicelearning might well be the most powerful pedagogy that delivers these types of outcomes and is most effective for preparing active global citizens. This speculation can be expanded to the other hybrid high-impact pedagogies that have been identified in this analysis and it warrants empirical evaluation. Do each of the first-, second-, and third-order hybrd high-impact pedagogies that include servicelearning produce outcomes that are more extensive, more robust, more transformational, and more distinctive than traditional pedagogies or a single high-impact practice? There are convincing reasons, both theoretical and empirical, to expect that this will be confirmed, although combining poor examples of high-impact pedagogies could result in the accumulation of deficiencies that result in a low-quality learning environment.

\section{What Service-Learning Brings to Hybrid High- Impact Pedagogies}

Reflection. Service-learning stresses the importance of incorporating regular and structured reflection to connect the activities of experiential learning to academic course content as well as personal growth and civic learning (Astin, Vogelge- sang, Ikeda, \& Yee, 2000; Clayton \& Ash, 2009a, 2009b; Eyler, Giles, \& Schmiede, 1996; Hatcher \& Bringle, 1997; Hatcher, Bringle, \& Muthiah, 2004; Sanders, Van Oss, \& McGeary, 2016; Zlotkowski \& Clayton, 2005). Conway et al.'s (2009) metaanalysis of service-learning's association with academic, personal, social, and citizenship outcomes found that structured reflection was associated with greater changes in these outcome measures than when there was an absence of structured reflection. Moely and Ilustre's (2014) research also showed that opportunities for reflection were positively associated with learning about the community and mastering academic content. Hatcher et al. (2004) found that quality of the learning environment of service-learning courses (i.e., active learning, course satisfaction, faculty interaction, peer interaction, perceived learning, personal relevance) was independently related to reflection activities that (a) clarified personal values, (b) were a regular part of the course, and (c) were structured with clear guidelines and directions. They also found that these qualities were more strongly related to course quality than was the amount of reflection. Subsequent research should determine if similar results are found for the hybrid high-impact pedagogies that incorporate service-learning and reflection.

The value of reflection intentionally designed around learning objectives is relevant to all applied and experiential learning (Ash \& Clayton, 2009a). Although the precise prevalence of reflection in the four high-impact pedagogies in this analysis is not known, I would speculate based on my professional experience that it is consistently present in service-learning, although the design of reflection regarding learning objectives, as illustrated by Ash and Clayton (2009a, 2009b; Bringle et al., 2016), can be greatly improved in most service-learning courses. For research, reflection is present although most likely confined to reflection that connects the research activities to academic content and less focused on personal growth and civic learning. Reflection is probably a severe deficiency of most internships, but there may be better structured and more frequent reflection in pre-professional courses (although most likely heavily concentrated on academic learning vs. personal growth and civic learning). For study away, including study abroad, systematic and well-structured reflection connecting the academic work and the experiential component (venue, educational and cultural aspects of the novel venue, diversity issues) is probably not existent or very weak, except for international servicelearning. Thus, what service-learning can bring to the other three high-impact pedagogies in this analysis, as well as all high-impact pedagogies, is a 
model for ensuring that reflection is an intentional part of course design and implementation, and that it aligns with a broad set of educational objectives (e.g., academic, civic, personal), as appropriate.

Partnerships. The literature on service-learning and civic engagement has differentiated between relationships (e.g., transactional interactions between persons; Bringle \& Clayton, 2013), partnerships (i.e., transformational relationships that involve closeness, equity, and integrity; Bringle \& Clayton, 2013), and democratic partnerships (i.e., inclusive, participatory, and fair; Saltmarsh et al., 2009). The SOFAR model of relationships (Bringle \& Clayton, 2013; Bringle, Clayton, \& Price, 2009; Clayton, Bringle, Senor, Huq, \& Morrison, 2010) identifies five constituencies typically involved in service-learning courses and relationships/partnerships between them: (a) Students, (b) staff at community-based Organizations, (c) Faculty, (d) campus Administrators (e.g., service-learning staff, executive leaders, deans, or department chairs), and (e) Residents of communities (or clients at community-based organizations). Any or all of these stakeholders can be considered partners who can collaborate and contribute in significant ways to the purposes and processes of instruction and any or all of the relationships between these constituencies can be developed to the benefit of each constituency. Service-learning stresses the importance of each person (faculty, staff, students, community constituencies) assuming roles as co-developers, co-learners, co-educators, and co-generators of knowledge (Dostilio et al., 2013). Service-learning brings a new paradigm to experiential education that incorporates the vision that these relationships can broaden the role of different persons (e.g., community partners, peers) as educators and broaden the epistemological basis for how learning occurs and what is learned. In addition, these relationships may not only be transactional but also transformational (Clayton et al., 2010) and democratic (i.e., fair, just, inclusive; Bringle et al., 2015; Saltmarsh et al., 2009). Service-learning provides models for partnerships with community partners that contribute new dimensions to the other high-impact practices and that can enrich the experiences for community partners (Bringle \& Clayton, 2013).

Diversity. Service-learning almost always has students involved with and collaborating with diverse others (O'Grady, 2000). Astin and Sax (1998) found that $38 \%$ of more than 3,000 college students surveyed engaged in service in order to "work with people who are different than me" (p. 255). Although not a majority, this finding indicates that there is interest among some students to interact with diverse others. But, in addition, there is room for educators to design courses that provide opportunities for other students to have educationally meaningful diversity experiences and develop appreciation for how diversity can contribute to their world view. Brandenberger and Bowman (2015) found across multiple institutions that active learning practices and diversity experiences contributed to prosocial growth from college entry to junior year. Bowman (2011), in a meta-analysis, found that face-to-face diversity experiences (vs. didactic educational experiences) were related to enhanced civic attitudes. Kilgo's (2015) research also supports the conclusion that diversity experiences and positive interactions with diverse peers mediated the positive effect that service-learning had on students' intercultural effectiveness. Most likely, each of the four highimpact pedagogies has the potential to contain diversity experiences, with the exception of traditional research and some internships (depending on the context and nature, they may not involve educationally-meaningful diversity experiences). However, the degree to which these diversity experiences are educationally meaningful with regard to clearly articulated learning objectives and structured reflection focused on diversity, intercultural competence, and cultural humility probably varies greatly and needs to be better understood. Pascarella et al. (2014) concluded: "Our findings with an objective, standardized measure of critical thinking skills support the conceptual argument that ... exposure to diversity experiences fosters the development of cognitive growth and more complex modes of thought" (p. 90). Furthermore, they noted that "The cognitive effect of diversity experiences appears to be sustained during 4 years of college and may even increase in magnitude over time" (p. 90). This conclusion needs to be replicated for service-learning courses and hybrid high-impact courses that include service-learning.

Adding service-learning to the other three high-impact pedagogies increases the likelihood that students in the hybrid high-impact courses will have diversity experiences that are well integrated with course design, learning objectives, reflection, partnerships, and assessment. Diversity is not only a mechanism for educational outcomes but it is also an educational outcome. For example, Rice and Horn (2014) found that service-learning contributed to enhancing "students' awareness and understanding of the complexities confronting diverse populations" ( $p$. 139). Thus, the addition of service-learning to other high-impact pedagogies can improve students' understanding of and sensitivity to diverse groups in society. 


\section{Conclusion}

The integration of service-learning courses into the curriculum during the past $25+$ years has had implications for assessment, faculty roles and rewards, institutional mission, and communitycampus partnerships. Further integration of servicelearning with other high-impact pedagogies may contribute to its capacity to produce institutional change and strengthen the public, civic, and democratic nature of the academy.

\section{References}

Ash, S. L., \& Clayton, P. H. (2009a). Generating, deepening, and documenting learning: The power of critical reflection for applied learning. Journal of Applied Learning in Higher Education, 1, 25-48.

Ash, S. L., \& Clayton, P. H. (2009b). Learning through critical reflection: A tutorial for students in servicelearning (Instructor version). Raleigh, NC: Authors.

Astin, A. W. (1999). Promoting leadership, service, and democracy: What higher education can do. In R. G. Bringle, R. Games, \& E. A. Malloy (Eds.), Colleges and universities as citizens (pp. 31-47). Needham Heights, MA: Allyn \& Bacon.

Astin, A. W., \& Sax, L. J. (1998). How undergraduates are affected by service participation. Journal of College Student Development, 39, 251-263.

Astin, A.W., Vogelgesang, L. J., Ikeda, E. K. \& Yee, J. A. (2000). How service-learning affects students. Los Angeles: Higher Education Research Institute.

Barefoot, B. O. (2008). Institutional structures and strategies for embedding civic engagement in the first college year. In M. J. LaBare (Ed.), First-year civic engagement: Sound foundations for college, citizenship, and democracy (pp. 23-25). New York: New York Times Knowledge Network.

Bowman, N. A. (2011). Promoting participation in a diverse democracy: A meta-analysis of college diversity experiences and civic engagement. Review of Educational Research, 81(1), 29-68.

Bowman, N. A., Brandenberger, J. W., Mick, C. A., \& Smedley, C. T. (2010). Sustained immersion courses and student orientations to equality, justice, and social responsibility: The role of short-term service-learning. Michigan Journal of Community Service Learning, 17(1), 20-31.

Bowman, N. A., \& Seifert, T. A. (2011). Can college students accurately assess what affects their learning and development? Journal of College Student Development, 52, 270-290.

Brandenberger, J. W., \& Bowman, N. A. (2015). Prosocial growth during college: Results of a national study. Journal of Moral Education, 44, 328-345.

Bringle, R. G., \& Clayton, P. H. (2012). Civic education through service-learning: What, how, and why? In L. McIlrath, A. Lyons, \& R. Munck (Eds.), Higher education and civic engagement: Comparative perspec- tives (pp. 101-124). New York: Palgrave.

Bringle, R. G., \& Clayton, P. H. (2013). Conceptual frameworks for partnerships in service learning. In P. H. Clayton, R. G. Bringle, \& J. A. Hatcher (Eds.). Research on service learning: Conceptual frameworks and assessment Vol. 2B: Communities, institutions, and partnerships (pp. 539-571). Arlington, VA: Stylus.

Bringle, R. G., Clayton, P. H., \& Bringle, K. E. (2015). Teaching democratic thinking is not enough: The case for democratic action. Partnerships: A Journal of Service-Learning \& Civic Engagement, 6(1), 1-26.

Bringle, R. G., Clayton, P. H. \& Plater, W. M. (2013). Assessing diversity, global, and civic learning: A means to change in higher education. Democracy and Diversity, 13(3), 4-6.

Bringle, R. G., Clayton, P. H., \& Price, M. F. (2009). Partnerships in service learning and civic engagement. Partnerships: A Journal of Service-Learning \& Civic Engagement, 1(1), 1-20.

Bringle, R. G., Games, R., \& Malloy, E. A. (Eds.) (1999a). Colleges and universities as citizens. Needham Heights, MA: Allyn \& Bacon.

Bringle, R. G., Games, R., \& Malloy, E. A. (1999b). Colleges and universities as citizens: Issues and perspectives. In R. G. Bringle, R. Games, \& E. A. Malloy (Eds.), Colleges and universities as citizens (pp. 1-16). Needham Heights, MA: Allyn \& Bacon.

Bringle, R. G., Games, R., \& Malloy, E. A. (1999c). Colleges and universities as citizens: Reflections. In R. G. Bringle, R. Games, \& E. A. Malloy (Eds.), Colleges and universities as citizens (pp. 193-204). Needham Heights, MA: Allyn \& Bacon.

Bringle, R. G., \& Hatcher, J. A. (1996). Implementing service learning in higher education. Journal of Higher Education, 67, 221-239.

Bringle, R. G., \& Hatcher, J. A. (1999). Reflection in service learning: Making meaning of experience. Educational Horizons, 77(4), 179-185.

Bringle, R. G., \& Hatcher, J. A. (2011). International service learning. In R. G. Bringle, J. A. Hatcher, \& S. G. Jones (Eds.), International service learning: Conceptual frameworks and research (pp. 3-28). Sterling, VA: Stylus.

Bringle, R. G., Hatcher, J. A., \& Jones, S. G. (Eds.). (2011). International service learning: Conceptual frameworks and research. Sterling, VA: Stylus.

Bringle, R. G., Phillips, M., \& Hudson, M. (2004). The measure of service learning: Research scales to assess student experiences. Washington, DC: American Psychological Association.

Bringle, R. G., \& Plater, W. M. (2017). Reflections on the Macquarie experience. In J. Sachs \& L. Clark (Eds.), Learning through community engagement: Vision and practice in higher education (pp. 301-319). Singapore: Springer.

Bringle, R. G., Reeb, R., Brown, M. A., \& Ruiz, A. (2016). Service learning in psychology: Enhancing undergraduate education for the public good. Washington, DC: American Psychological Association.

Cambridge, B. L. (1999). Effective assessment: A signal 
of quality citizenship. In R. G. Bringle, R. Games, \& E. A. Malloy (Eds.), Colleges and universities as citizens (pp. 173-192). Needham Heights, MA: Allyn \& Bacon.

Celio, C. I., Durlak, J., \& Dymnicki, A. (2011). A metaanalysis of the impact of service-learning on students. Journal of Experiential Education, 34, 164-181.

Clayton, P. H., Bringle, R. G., \& Hatcher, J. A. (Eds.). (2013). Research on service learning: Conceptual frameworks and assessment. Vol. 2A: Students and faculty. Arlington, VA: Stylus.

Clayton, P. H., Bringle, R. G., Senor, B., Huq, J., \& Morrison, M. (2010). Differentiating and assessing relationships in service-learning and civic engagement: Exploitive, transactional, and transformational. Michigan Journal of Community Service Learning, 16(2), 5-21.

Conway, J. M., Amel, E. L., \& Gerwien, D. P. (2009). Teaching and learning in the social context: A metaanalysis of service learning's effects on academic, personal, social, and citizenship outcomes. Teaching of Psychology, 36, 233-245.

Dostilio, L., Brackmann, S., Edwards, K., Harrison, B., Kliewer, B. K., \& Clayton, P. H. (2013). Reciprocity: Saying what we mean and meaning what we say. Michigan Journal of Community Service Learning, 19(1), 17-32.

Dunning, D., Heath, C., \& Suls, J. M. (2004). Flawed self-assessment: Implications for health, education, and the workplace. Psychological Science in the Public Interest, 5, 69-106.

Eyler, J., Giles, D. E., Jr., \& Braxton, J. (1997). The impact of service-learning on college students. Michigan Journal of Community Service Learning, 4, 5-15.

Eyler, J., Giles, D. E., Jr., \& Schmiede, A. (1996). A practitioner's guide to reflection in service-learning: Student voices and reflections. Nashville, TN: Vanderbilt University.

Finley, A. (2011). Assessment of high-impact practices: Using findings to drive change in the Compass Project. Peer Review, 13(2), 29-33.

Finley, A., \& McNair, T. (2013). Assessing underserved students' engagement in high impact practices. Washington, DC: Association of American Colleges and Universities.

Furco, A. (1996). Service-learning: A balanced approach to experiential education. In Corporation for National Service (Ed.), Expanding boundaries: Serving and learning (pp. 2-6). Columbia, MD: The Cooperative Education Association.

Gibbons, M., Limoges, C., Nowotny, H., Schwartzman, S., Scott, P., \& Trow, M. (1994). The new production of knowledge: The dynamics of science and research in contemporary societies. Thousand Oaks, CA: Sage.

Glassick, C.E. (1999). Ernest L. Boyer: Colleges and universities as citizens. In R. G. Bringle, R. Games, \& E. A. Malloy (Eds.), Universities and colleges as citizens (pp. 17-30). Needham Heights, MA: Allyn \& Bacon.

Green, P. M., \& Johnson, M. (Eds.). (2014). Crossing boundaries: Tension and transformation in international service-learning. Sterling, VA: Stylus.
Hansel, N. (Ed.). (2012). Characteristics of excellence in undergraduate research. Washington, DC: Council on Undergraduate Research.

Hansen, M. J., \& \& Hahn, T. (2016, February). Themed learning communities and service learning leveraged for student success. Paper presented at the annual conference on the First-Year Experience, Orlando, FL.

Hartman, E., \& Kiely, R. (2014). A critical global citizenship. In M. Johnson \& P. M. Green (Eds.), Crossing boundaries: Tension and transformation in international service-learning (pp. 215-242). Sterling, VA: Stylus.

Hatcher, J. A. (2008). The public role of professionals: Developing and evaluating the civic-minded professional scale (Doctoral dissertation). Retrieved from https://scholarworks.iupui.edu/handle/1805/1703.

Hatcher, J. A., \& Bringle, R. G. (1997). Reflection: Bridging the gap between service and learning. Journal of College Teaching, 45, 153-158.

Hatcher, J. A., Bringle, R. G., \& Hahn, T. W. (2017a). Introduction to research on service learning and student civic outcomes. In J. A. Hatcher, R. G. Bringle, \& T. W. Hahn (Eds.), Research on service learning and student civic outcomes (pp. 3-24). Sterling, VA: Stylus.

Hatcher, J. A., Bringle, R. G., \& Hahn, T. W. (Eds.). (2017b). Research on service learning and student civic outcomes: Conceptual frameworks and methods. Sterling, VA: Stylus.

Hatcher, J. A., Bringle, R. G., \& Muthiah, R. (2004). Designing effective reflection: What matters to servicelearning? Michigan Journal of Community Service Learning, 11(1), 38-46.

Henscheid, J. M. 2000. Professing the disciplines: An analysis of senior seminars and capstone courses (Monograph No. 30). Columbia, SC: University of South Carolina, National Resource Center for The First-Year Experience and Students in Transition.

Higher Education Quality Council of Ontario (2016). A practical guide for work-integrated learning. Toronto, Ontario, Canada: Queen's Printer for Ontario.

Hill, P. L., Pasquesi, K., Bowman, N. A., \& Brandenberger, J. W. (2017). Longitudinal research and student civic outcomes. In J. A. Hatcher, R. G. Bringle, \& T. Hahn (Eds.), Research on student civic outcomes in service learning: Conceptual frameworks and methods (pp. 283-302). Sterling, VA: Stylus.

Holland, B. A. (1999). From murky to meaningful: The role of mission in institutional change. In R. G. Bringle, R. Games, \& E. A. Malloy (Eds.), Colleges and universities as citizens (pp. 48-73). Needham Heights, MA: Allyn \& Bacon.

Holland, B. A., \& Furco, A. (2004). Institutionalizing service-learning in higher education: Issues and strategies for chief academic officers. In M. Langseth \& W. M. Plater (Eds.), Public work and the academy. An academic administrator's guide to civic engagement and service learning (pp. 23-39). Bolton, MA: Anker.

Hovey R., \& Weinberg, A. (2009). Global learning and the making of citizen diplomats. In R. Lewin (Ed.), Study abroad and the making of global citizens: High- 
er education and the quest for global citizenship (pp. 33-48). New York: Routledge.

Jacoby, B. (2014). Service-learning essentials: Questions, answers, and lessons learned. San Francisco: Jossey-Bass.

Janke, E. M., \& Domagal-Goldman, J. M. (2017). Institutional characteristics and student civic outcomes. In J. A. Hatcher, R. G. Bringle, \& T. Hahn (Eds.), Research on student civic outcomes in service learning: Conceptual frameworks and methods (pp. 261-282). Sterling, VA: Stylus.

Jones, S. G., \& Steinberg, K. S. (2011). An analysis of international service learning programs. In R. G. Bringle, J. A. Hatcher, \& S. G. Jones (Eds.), International service learning: conceptual frameworks and research (pp. 89-112). Sterling, VA: Stylus.

Jones, S. R., \& Foste, Z. (2017). Qualitative research on service learning and student civic outcomes. In J. A. Hatcher, R. G. Bringle, \& T. Hahn (Eds.), Research on student civic outcomes in service learning: Conceptual frameworks and methods (pp. 241-260). Sterling, VA: Stylus.

Jones, S. R., Rowan-Kenyon, H. T., Ireland, S. M., Niehaus, E., \& Skendall, K. C. (2012). The meaning students make as participants in short-term immersion programs. Journal of College Student Development, 53, 201-220.

Kecskes, K., \& Kerrigan, S. (2009). Capstone experiences. In B. Jacoby (Ed.), Civic engagement in higher education: Concepts and practices (pp. 117-139). San Francisco: Jossey-Bass.

Kiely, R., \& Hartman, E. (2011). Qualitative research methodology and international service learning. In R. G. Bringle, J. A. Hatcher, \& S. G. Jones, (Eds.). International service learning: Conceptual frameworks and research (pp. 291-318). Sterling, VA: Stylus.

Kilgo, C. A. (2015). The estimated effects of service learning on students' intercultural effectiveness. Journal of College Student Development, 16, 867-871.

Kilgo, C. A., Sheets, J. K. E., \& Pascarella, E. T. (2015). The link between high-impact practices and student learning: Some longitudinal evidence. Higher Education, 69, 509-525.

Kolek, E. A. (2013). Can we count on counting? An analysis of the validity of community engagement survey measures. The International Journal of Research on Service-Learning and Community Engagement, 1, 92108.

Kowaleski, B. M. (2004). Service-learning taken to a new level through community-based research: A win-win for campus and community. In M. Welch \& S. H. Billig (Eds.), New perspectives in service-learning: Research to advance the field (pp. 127-147). Greenwich, CT: Information Age Publishing.

Kuh, G. D. (2009). High-impact educational practices. Washington, DC: Association of American Colleges and Universities.

Kuh, G. D. (2012, April). A closer look at selected highimpact practices. Paper presentation at the Kentucky Council on Postsecondary Education, Louisville, KY.
Marchese, T. J. (1997). The new conversation about learning: Insights from neuroscience and anthropology, cognitive studies and work-place studies. In American Association for Higher Education (Ed.), Assessing impact: Evidence and action (pp. 79-95). Washington: American Association for Higher Education.

Maupome, G., Martinez-Mier, E. A., Holt, A., MedinaSolís, C. E., Mantilla-Rodríguez, A., \& Carlton, B. (2013). The association between geographical factors and dental caries in a rural area in Mexico. Cadernos de Saude Publica, 29, 1407-1414.

Mayhew, M. J., \& Engberg, M. E. (2011). Promoting the development of civic responsibility: Infusing servicelearning practices in first-year "success" courses. Journal of College Student Development, 52, 20-38.

Minkler, M., \& Freudenberg, N. (2010). From community-based participatory research to policy change. In H. Fitzgerald, C. Burack, \& S. Seifer (Eds.), Handbook of engaged scholarship: Contemporary landscapes, future directions: Volume 2: Communitycampus partnerships (pp. 275-294). East Lansing, MI: Michigan State University Press.

Moely, B., \& Ilustre, V. (2014). The impact of servicelearning course characteristics on university students' learning outcomes. Michigan Journal of Community Service Learning, 21(1), 5-16.

Novak, J. M.., Markey, V., \& Allen, M. (2007). Evaluating cognitive outcomes of service learning in higher education: A meta-analysis. Communication Research Reports, 24(2), 149-157.

O'Grady, C. (Ed.). (2000). Integrating service-learning and multicultural education in colleges and universities. Mahwah, NJ: Lawrence Erlbaum.

O'Neill, N. (2010). Internships as a high-impact practice: Some reflections on quality. Peer Review, 12(4), 4-8.

Pascarella, E. T., Martin, G. L., Hanson, J. M., Trolian, T. L., Gillig, B., \& Blaich, C. (2014). Effects of diversity experiences on critical thinking skills over 4 years of college. Journal of College Student Development, 95(1), 86-92.

Pascarella, E. T., \& Terenzini, P. T. (2005). How college affects students: Vol. 2. A third decade of research. San Francisco: Jossey-Bass.

Patton, M. Q. (2013). Improving rigor in service-learning research. In J. A. Hatcher \& R. G. Bringle (Eds.), Understanding service-learning and community engagement: Crossing boundaries through research (pp. 3-9). Charlotte, NC: Information Age Publishing.

Plater, W. M. (1999). Habits of living: Engaging the campus as citizen one scholar at a time. In R. G. Bringle, R. Games, \& E. A. Malloy (Eds.), Colleges and universities as citizens (pp. 141-172). Needham Heights, MA: Allyn \& Bacon.

Reeb, R. N., Farmer, C. N., Glendening, Z. S., \& Kinsey, R. (2014, August). Application of psycho-ecological systems model: Behavioral activation in homeless shelters. Poster presented at the annual meeting of the American Psychological Association, Washington, DC.

Rice, J. S., \& Horn, T. (2014). Teaching diversity through 
service-learning: An integrative praxis pedagogical approach. Journal on Excellence in College Teaching, 25(1), 139-157.

Saltmarsh, J., Hartley, M., \& Clayton, P. H. (2009). Democratic engagement white paper. Boston: New England Resource Center for Higher Education.

Sanders, M. J., Van Oss, T., \& McGeary, S. (2016). Analyzing reflections in service learning to promote personal growth and community self-efficacy. Journal of Experiential Education, 39(1), 78-88.

Savicki, V., \& Brewer, E. (2015). Assessing study abroad: Theory, tools, and practice. Sterling, VA: Stylus.

Singleton, S., Hirsch, D., \& Burack, C. (1999). Organizational structures for community engagement. In R. G. Bringle, R. Games, \& E. A. Malloy (Eds.), Colleges and universities as citizens (pp. 121-140). Needham Heights, MA: Allyn \& Bacon.

Sobania, N. (Ed.) (2015). Putting the local in global education: Models for transformative learning through domestic off-campus programs. Sterling, VA: Stylus.

Sobania, N., \& Braskamp, L. A. (2009). Study abroad or study away: It's not merely semantics. Peer Review, 11(4). Retrieved from https://www.aacu.org/publications-research/periodicals/study-abroad-or-studyaway-its-not-merely-semantics

Staub, S., \& Finley, A. (2009). Service learning and learning communities: Promising pedagogies. Diversity \& Democracy, 12(2), 18-19.

Steinberg, K. Bringle, R. G., \& McGuire, L. E. (2013). Attributes of quality research in service learning. In P. H. Clayton, R. G. Bringle, \& J. A. Hatcher (Eds.). Research on service learning: Conceptual frameworks and assessment. Vol. 2A: Students and faculty (pp. 2753). Arlington, VA: Stylus.

Steinberg, K. S., Bringle, R. G., \& Williams, M. J. (2010). Service learning research primer. Scotts Valley, CA: National Service-Learning Clearinghouse.

Stokamer, S. T., \& Clayton, P. H. (2017). Study civic learning through service learning: instructional design and research. In J. A. Hatcher, R. G. Bringle, \& T. Hahn (Eds.), Research on student civic outcomes in service learning: Conceptual frameworks and methods (pp. 45-65). Sterling, VA: Stylus.

Strand, K. J., Cutforth, N., Stoecker, R., Marullo, S., \& Donohue, P. (2003). Community-based research and higher education: Principles and practices. San Francisco: Jossey-Bass.

Swaner, J. E., \& Brownell, L. E. (2009). Outcomes of high impact practices for underserved students: A review of the literature. Washington, DC: Association of American Colleges and Universities.

Van de Ven, A. H. (2007). Engaged scholarship: A guide for organizational and social research. New York: Oxford University Press.

Walshok, M. L. (1999). Strategies for building the infrastructure that supports the engaged campus. In R. G.
Bringle, R. Games, \& E. A. Malloy (Eds.), Colleges and universities as citizens (pp. 74-95). Needham Heights, MA: Allyn \& Bacon.

Warren, J. L. (2012). Does service-learning increase student learning?: A meta-analysis. Michigan Journal of Community Service Learning, 18(2), 56-61.

Whitney, B. C., \& Clayton, P. H. (2011). Research on the role of reflection in international service learning. In R. G. Bringle, J. A. Hatcher, \& S. G. Jones, (Eds.). International service learning: Conceptual frameworks and research (pp. 145-187). Sterling, VA: Stylus.

Yorio, P. L., \& Ye, F. (2012). A meta-analysis on the effects of service-learning on the social, personal, and cognitive outcomes of learning. Academy of Management Learning \& Education, 11(1), 9-27.

Zlotkowski, E, (1999). Pedagogy and engagement. In R. G. Bringle, R. Games, \& E. A. Malloy (Eds.), Colleges and universities as citizens (pp. 96-120). Needham Heights, MA: Allyn \& Bacon.

Zlotkowski, E., \& Clayton, P. H. (2005, April). Reclaiming reflection. Paper presented at the Gulf South Summit on Service-learning and Civic Engagement, Cocoa Beach, FL.

\section{Author}

ROBERT G. BRINGLE (rbringle@iupui.edu) is currently Chancellor's Professor Emeritus of Psychology and Philanthropic Studies and Senior Scholar in the Center for Service and Learning at Indiana University-Purdue University Indianapolis (IUPUI). From 2012-2015, he was the Kulynych/ Cline Visiting Distinguished Professor of Psychology at Appalachian State University. He served as Executive Director of the IUPUI Center for Service and Learning from 1994-2012. In 2017, he published Research on Student Civic Outcomes in Service Learning (with J. Hatcher \& T. Hahn). Bringle was awarded the Thomas Ehrlich Faculty Award for Service Learning, the IUPUI Chancellor's Award for Excellence in Teaching, and the Legacy of Service Award from Indiana Campus Compact. He was recognized at the International Association for Research on Service-Learning and Community Engagement conference for his outstanding contributions to the service-learning research field. The University of the Free State, South Africa, awarded him an honorary doctorate for his scholarly work on civic engagement and service learning. In 2016, he was inducted into the Academy for Civic Engagement Scholarship. 